This is a postprint (final draft post-refereeing) of an article accepted for publication in The Electronic Library 31 (6), 781-791, 2013

\title{
Use of social networks for academic purposes: a case study
}

\author{
Gemma Nández \\ Biblioteca, Universitat Pompeu Fabra, Barcelona (Spain) \\ gemma.nandez@upf.edu
}

Ángel Borrego

Facultat de Biblioteconomia i Documentació, Universitat de Barcelona (Spain)

borrego@ub.edu

\section{Introduction}

Access to scientific information has progressed enormously both qualitatively and quantitatively during the last two decades due to the improvement in discovering tools - alert services, databases, metasearch engines, online catalogues, publisher platforms, and so on - together with the increase in the amount of electronic information available to end users.

Extensive research has tracked how electronic publishing is influencing the informationseeking and reading behaviour of scholars. Tenopir et al. (2009) showed that scholars' use of electronic information has increased substantially over time as academic libraries transit from print to electronic collections. The adoption of electronic information in academic settings has been extremely successful. Despite minor disciplinary differences - more related to the amount of electronic information available in each field than to substantial differences in scholars' inclination towards the use electronic resources electronic databases and journals have been rapidly adopted by scholars. Recent research in the United Kingdom (Nicholas et al., 2010) shows that academic journals are central to all academic fields and that the electronic form is the prime means of access. Similarly, in the United States, Niu et al. (2010) report the predominance of the use of electronic methods for searching and accessing scholarly content.

Among the most recent developments in the creation and communication of information in electronic format are the social media, a term that refers to a set of web technologies that allow the creation and exchange of user-generated content. According to the OECD (2007, p. 11), user-generated content must meet three requirements: it must be publicly available over the Internet; it must show a certain amount of creative effort; and it must have been compiled outside professional routines and practices. Based on this definition and on a set of theories in the field of media research and social processes, Kaplan and Haenlein (2010) classify social media in six categories: collaborative projects, blogs and microblogs, content communities, social networking sites, virtual game worlds, and virtual social worlds. The unifying term "Web 2.0" is closely related to the concept of social media. This term refers to technologies characterized as being user-centred, open, participatory, interactive and knowledge sharing (Gu and Widén-Wulff, 2011).

Since social media are intended to support the collaborative creation and dissemination of knowledge, it is not surprising that scholars have explored their use for academic purposes, and that a number of social media services specifically targeted at the academic community - blogs, online comments to articles, social bookmarking sites, wikis, websites to post slides, text or videos, etc. - have emerged in the last few years. According to a Research Information Network study based on an online survey 
This is a postprint (final draft post-refereeing) of an article accepted for publication in The Electronic Library 31 (6), 781-791, 2013

followed by in-depth interviews (Procter et al., 2010; RIN, 2010), most researchers make at least occasional use of these tools and services for purposes related to their research. Social media are used at all points of the research cycle, from identifying research opportunities to disseminating research results. According to the results of a large international survey conducted by Rowlands et al. (2011), the most popular tools are those that allow collaborative authoring, conferencing, and scheduling and meeting tools. Although Nicholas et al. (2010) were surprised at the absence of social media sources in their study on the scholarly behaviour of researchers in the United Kingdom, a similar study conducted in the United States (Niu et al., 2010) highlighted a notable trend in the use of collaborative technology for sharing information with colleagues and students. Social media may afford informal communication similar, or in some cases superior to, the channels of informal communication for dissemination and collaboration purposes traditionally used by scholars — face-to-face interactions with colleagues, seminars, conferences, etc.

This study deals with the use of a specific category of social media, social networking sites, for academic purposes. Boyd and Ellison (2008) define social networking sites as web-based services that allow individuals to construct a public or semi-public profile within a bounded system, articulate a list of other users with whom they share a connection, and view and traverse their list of connections and those made by others within the system. In a similar way, Kaplan and Haenlein (2010) state that social networking sites "enable users to connect by creating personal information profiles, inviting friends and colleagues to have access to those profiles, and sending e-mails and instant messages between each other.” Facebook is, at present, the largest social networking site.

The reason for focusing our research on social networking sites is the lack of specific studies on their use in academic contexts; most results are camouflaged in larger studies on the use of social media. These studies show that there are differences in the use of the various categories of social media, a situation that calls for an individual analysis of the user profiles and the benefits derived from each one. For instance, according to the RIN (2010) results, frequent users of social networking sites are occasional, rather than regular, users of other Web 2.0 tools and services. The demographic profile of users also varies, with junior and younger researchers more likely to be frequent users of social networking sites, whereas, contrary to stereotypes, older age groups and those in senior positions are regular users of other Web 2.0 tools. Rowlands et al. (2011) showed that the use of social networking sites was much lower than other social media tools, with Facebook being by far the most popular service. A recent paper by Ponte and Simon (2011) analysed the impact of Web 2.0 tools on the scholarly communication process. Consistent with Rowlands' results, they found that about one-third of researchers use social networks, falling short of wikis and blogs. Gu and Widén-Wulff (2011) also explored whether social media affect scholarly communication processes through a survey sent to researchers and employees at a Finnish university. Their results show that although most academics know about social networks, they use them much more in everyday life than in their research or teaching work.

Understanding changes in how electronic resources alter scholars' information behaviour provides insights into how libraries and publishers can react and contribute to those changes. This paper focuses on the use of social networking sites among academics. As a case study, we assessed scholars at Catalan universities who use 
This is a postprint (final draft post-refereeing) of an article accepted for publication in The Electronic Library 31 (6), 781-791, 2013

Academia.edu, a networking site for academics which works in a similar fashion to Facebook, and allows users to upload their publications and share them with other scholars. Users can also follow other academics and receive notifications about their papers and other research updates. According to the service, in February 2012 more than a million users had an account on the platform. Specifically, the study is underpinned by the following questions:

(1) What is the demographic profile of the users of an academic social network in terms of age, sex, professional category and field of knowledge?

(2) What are their reasons for using a social networking site and how intensively do they use it?

(3) Do they use any other social media for research purposes? If so, what benefits do they gain from them?

\section{Methodology}

The study was carried out in two stages. In the first stage, we examined the profiles of the users of Academia.edu, who were affiliated with twelve Catalan universities (seven public universities, four private universities and one online university). For each profile, the sex of the researcher, the number of uploaded documents, the number of followers and the number of persons being followed by the researcher were recorded.

In the second stage of the study, a survey was sent in June 2011 to the 766 individuals who included an email address in their Academia.edu profile. The questionnaire was distributed electronically through a survey manager solution developed by Netquest, a Spanish market research company. Three reminders followed in June and July 2011. Sixteen emails were returned because the email address was invalid. A total of 293 subjects replied to the survey (39\%) and their answers are those analysed in this article.

The survey was structured in four parts. The first three questions asked about the demographic characteristics (age, category and field of knowledge) of the informants. Then, three questions dealt with the usage of Academia.edu. Informants were asked about their reasons for using the service, their frequency of use and the length of sessions. Three further questions focused on the use of other social media tools (defined by examples) for academic purposes, the adequacy of these tools for the intended aims and the support for the use of these services that respondents received at their home institutions. Finally, an open-ended question collected other opinions.

Instead of addressing a representative sample of the academic community and gathering data on their use of social media, the research was targeted at a group of scholars who already have a profile on a social networking site. By aiming the research at academics who are already active users of a social network, we can assume that those replying to the survey had good knowledge of the subject under investigation. However, the results cannot be extrapolated to a larger set of academics.

\section{Results}

\section{Profile of the social networking site users}

A total of 1,263 individuals affiliated with eleven of the twelve Catalan universities (there were no users from one of the universities) had a profile on Academia.edu: 752 
This is a postprint (final draft post-refereeing) of an article accepted for publication in The Electronic Library 31 (6), 781-791, 2013

were males (60\%) and 507 females (40\%). It was not possible to determine the sex of four users.

According to the professional categories defined by the service, more than half of the users (55\%) classified themselves as academics, including in this category "faculty members" and "department members". Nearly one-third of the users classified themselves as "graduate students" (32\%), with smaller percentages of "postdocs" (6\%) and "alumni" (5\%).

Table 1 . Users by category

\begin{tabular}{|l|r|r|}
\hline & $\mathrm{n}$ & $\%$ \\
\hline Faculty member & 545 & 43.2 \\
\hline Graduate student & 399 & 31.6 \\
\hline Department member & 152 & 12.0 \\
\hline Postdoc & 78 & 6.2 \\
\hline Alumni & 60 & 4.8 \\
\hline Undergraduate & 12 & 1.0 \\
\hline Emeritus & 4 & 0.3 \\
\hline Other & 5 & 0.4 \\
\hline Total & 1,263 & 100.00 \\
\hline
\end{tabular}

One of the options in the Academia.edu profile is to upload publications or to insert a link to the source of these publications. A quarter of the users had taken advantage of this option, mainly to provide access to "papers", in the terminology used by Academia.edu. A smaller percentage of users published documents classified as "books" (7\%) and "talks" (4\%), whereas the presence of "teaching documents" was minimal (2\%). "Papers" were the most popular type of document uploaded, with an average of nine papers per user for those individuals with this kind of document in their profile. However, the high standard deviation indicates that only a small number of very active users had a large number of papers in their profiles.

Table 2. Documents uploaded to the academics’ profiles

\begin{tabular}{|l|r|r|c|}
\hline & \multicolumn{2}{|c|}{ Users } & $\begin{array}{c}\text { Average number of } \\
\text { documents per user (SD) }\end{array}$ \\
\hline & $\mathrm{n}$ & $\%$ & \\
\hline Papers & 318 & 25.2 & $9.11(11.48)$ \\
\hline Books & 94 & 7.4 & $3.38(3.63)$ \\
\hline Talks & 44 & 3.5 & $4.75(6.04)$ \\
\hline Teaching documents & 23 & 1.8 & $2.65(2.67)$ \\
\hline
\end{tabular}

One of the main features of social networking sites is the option to create networks among users. In Academia.edu, academics can follow the activity of other scholars and receive notifications when these scholars modify their profiles by uploading new publications, for instance. However, a quarter of the users of Academia.edu (26\%) did not follow any other academics. Most of those who followed other scholars did so with less than ten people (56\%). The results were similar in the opposite direction, with twothirds of academics (66\%) having from one to ten followers. 
This is a postprint (final draft post-refereeing) of an article accepted for publication in The Electronic Library 31 (6), 781-791, 2013

Table 3. Followers and academics being followed

\begin{tabular}{|l|r|r|r|r|}
\hline & \multicolumn{2}{|c|}{ Following the work of } & \multicolumn{2}{c|}{ Work being followed by } \\
\hline & $\mathrm{n}$ & $\%$ & $\mathrm{n}$ & $\%$ \\
\hline 0 & 328 & 26.0 & 209 & 16.5 \\
\hline $1-10$ & 712 & 56.4 & 830 & 65.7 \\
\hline $11-20$ & 117 & 9.3 & 121 & 9.6 \\
\hline $21-30$ & 44 & 3.5 & 55 & 4.4 \\
\hline $31-40$ & 27 & 2.1 & 22 & 1.7 \\
\hline $41-50$ & 11 & 0.9 & 11 & 0.9 \\
\hline$>50$ & 24 & 1.9 & 14 & 1.1 \\
\hline
\end{tabular}

\section{Survey for social networking site users}

A total of 293 answers to the questionnaire were obtained. The respondents were from all the age ranges, with a higher presence of those in the thirty-one to forty age group (37\%), forty-one to fifty (25\%) and twenty to thirty (24\%). The remaining $14 \%$ were older than fifty-one.

Half of the respondents were academics (50\%), including full professors, permanent, non-permanent and part-time lecturers. This category was followed by $\mathrm{PhD}$ students (29\%). Fewer respondents were postdocs (9\%) and students (2\%). The remaining $10 \%$ ticked the option "other" and were mostly respondents who shared two of these categories, for instance, a part-time lecturer who was also a $\mathrm{PhD}$ student. As could be expected, there was a significant relationship between age and category, with a higher proportion of younger respondents - i.e. those under thirty- being students, whereas most lecturers were over 40 years old $\left(\chi^{2}=145.367, \mathrm{df}=9, \mathrm{p}<0.01\right)$.

By field of knowledge, nearly half of the respondents (47\%) were social sciences scholars. They were followed by academics in the arts and humanities (22\%), exact and natural sciences (12\%), engineering (11\%) and health sciences (4\%). Twelve respondents (4\%) did not classify themselves in any of these categories.

The three main reasons for using Academia.edu were to get in touch with other researchers (67\%), to disseminate research output (61\%) and to follow other researchers' activities (59\%). Forty per cent of users joined the service to disseminate their curriculum vitae. The main reasons for using the service were the same among all user categories and fields of knowledge. However, there was a statistically significant relationship between user category and the use of Academia.edu to disseminate curriculum vitae. A higher proportion of students, postdocs, non-permanent and parttime lecturers used the service for this purpose, to the detriment of permanent lecturers $\left(\chi^{2}=13.038, \mathrm{df}=3, \mathrm{p}<0.01\right)$. 
This is a postprint (final draft post-refereeing) of an article accepted for publication in The Electronic Library 31 (6), 781-791, 2013

Table 4. Reasons for using an academic social network

\begin{tabular}{|l|r|r|}
\hline & $\mathrm{n}$ & $\%$ \\
\hline Get in touch with other researchers & 197 & 67.2 \\
\hline Disseminate research output (papers, conference presentations, etc.) & 180 & 61.4 \\
\hline Follow other researchers' activities & 172 & 58.7 \\
\hline Disseminate curriculum vitae & 116 & 39.6 \\
\hline $\begin{array}{l}\text { No specific aim, signed up because other researchers from the } \\
\text { department/faculty are there }\end{array}$ & 64 & 21.8 \\
\hline Find collaborators for research projects & 49 & 16.7 \\
\hline Disseminate teaching material (notes, class slides, etc.) & 33 & 11.3 \\
\hline Search for a job & 25 & 8.5 \\
\hline Other & 18 & 6.2 \\
\hline
\end{tabular}

A total of $22 \%$ of the respondents claimed that they did not have any particular aim in mind when they created their profile for the service; they just wanted to be there as other colleagues were. Seventeen per cent of users wanted to find collaborators for research projects, $11 \%$ aimed to disseminate their teaching materials and $9 \%$ thought the service could be useful to find a job. Users who ticked the "other" option indicated that they used their profile as their personal website or found it useful to know more about their web visibility, since the service informs users when their profile is viewed as a result of a search engine search. Other users stated that they used the service to follow journals in their field or just because they have been invited by other researchers.

Users were also asked how often they logged on to the service. Most (35\%) stated that they visited the social network website when they received an email from the service or sporadically (34\%). The remaining users quantified their visits as monthly (13\%), weekly (13\%) or daily (5\%). The visits were short. Nearly three-quarters of the respondents (72\%) stated that they spent less than 15 minutes per visit, while $24 \%$ stated that they spent between 15 and 30 minutes per session. The remaining $4 \%$ spent between 30 minutes and an hour per visit.

When asked about the use of other social media for academic purposes, around threequarters of the respondents claimed to use citation indexes, document creation, edition and sharing tools, and communication tools. These services were followed by reference management software (68\%) and time management tools (66\%).

A total of $59 \%$ of the users of Academia.edu were present in other general social networks. Forty-five per cent used instant messaging services, $45 \%$ used audiovisual management tools for video and 38\% used them for images. Around a third of the respondents used tools for the creation and edition of presentations (37\%), social bookmarking tools (36\%), blogs and wikis (35\%), services to manage surveys (35\%), microblogging (32\%) and scientists' databases (30\%). Other scientific social networks (18\%) and research platforms (7\%) were among the services that were least employed. 
This is a postprint (final draft post-refereeing) of an article accepted for publication in The Electronic Library 31 (6), 781-791, 2013

Table 5. Social media used for academic purposes

\begin{tabular}{|l|r|r|}
\hline & $\mathrm{n}$ & $\%$ \\
\hline Citations indexes (Google Scholar, CiteSeer, getCITED) & 221 & 75.4 \\
\hline $\begin{array}{l}\text { Document creation, edition and sharing (Google Docs, Syncplicity, } \\
\text { Docs.com, Dropbox, etc) }\end{array}$ & 218 & 74.4 \\
\hline Communication (Skype, Google Talk) & 218 & 74.4 \\
\hline $\begin{array}{l}\text { Reference management software (RefWorks, Zotero, Mendeley, } \\
\text { EndNote, CiteULike) }\end{array}$ & 199 & 67.9 \\
\hline Time management (Google Calendar, Doodle) & 192 & 65.5 \\
\hline $\begin{array}{l}\text { General social networks (Facebook, Hi5, Ning, LinkedIn, MySpace, } \\
\text { Yammer, Xing, Orku, Plaxor) }\end{array}$ & 173 & 59.0 \\
\hline $\begin{array}{l}\text { Videos (sevenload, Viddler, Vimeo, YouTube, Dailymotion, Metacafe, } \\
\text { Nico Nico Douga, Openfilm) }\end{array}$ & 133 & 45.4 \\
\hline Instant messaging (Msn) & 132 & 45.1 \\
\hline $\begin{array}{l}\text { Images and photographs (deviantArt, Flickr, Photobucket, Picasa, } \\
\text { SmugMug, Zooomr) }\end{array}$ & 110 & 37.5 \\
\hline $\begin{array}{l}\text { Presentations: creation, edition and sharing (SlideShare, Prezi, } \\
\text { Empressr) }\end{array}$ & 108 & 36.9 \\
\hline $\begin{array}{l}\text { Social bookmarking (Delicious, Google Reader, 2collab, Connotea, } \\
\text { StumbleUpon, folkd) }\end{array}$ & 105 & 35.8 \\
\hline $\begin{array}{l}\text { Blogs and wikis (Science Blogs, MADRI+D, PLoS Blog, Open Wet } \\
\text { Ware) }\end{array}$ & 103 & 35.2 \\
\hline $\begin{array}{l}\text { Surveys (SurveyMonkey, Survey Gizm, Free Online Surveys, } \\
\text { SurveysPro, Google Forms) }\end{array}$ & 102 & 34.8 \\
\hline $\begin{array}{l}\text { Microblogging (Twitter, FMyLife, Foursquare, Jaiku, Plurk, Posterous, } \\
\text { Tumblr, Qaiku, Google Buzz) }\end{array}$ & 95 & 32.4 \\
\hline Scientists' databases (Researcher ID, Emerald Research Connections) & 82 \\
\hline $\begin{array}{l}\text { Science news services (SciTopics, Wikio, ScienceDaily, Science 2.0, } \\
\text { Science News) }\end{array}$ & 62.0 \\
\hline $\begin{array}{l}\text { Scientific social networks (Academici, Epernicus, Lalisio, } \\
\text { Methodspace, ResearchGate, Sciencestage) }\end{array}$ & 7.2 \\
\hline $\begin{array}{l}\text { Research platforms (HUBzero, NanoHUB, MyExperiment, } \\
\text { NatureNetwork, Arts-humanities.net) }\end{array}$ & 53.2 \\
\hline
\end{tabular}

The respondents were asked to evaluate on a scale of one to seven the benefits of using social media for a series of purposes. In the box plots in Figure 1, the line within the boxes represents the median score for each category and the left and right boundaries of the box represent the twenty-fifth and the seventy-fifth percentiles. As can be observed, academics particularly value the use of social media to share materials and follow other scholars' activities (Median=6). To a lesser extent, they value social media tools to disseminate their academic activities, meet other researchers and remain up-to-date in their fields (Median=5). The remaining purposes were valued with a median of four points. 
This is a postprint (final draft post-refereeing) of an article accepted for publication in The Electronic Library 31 (6), 781-791, 2013

Figure 1. Benefits derived from social media

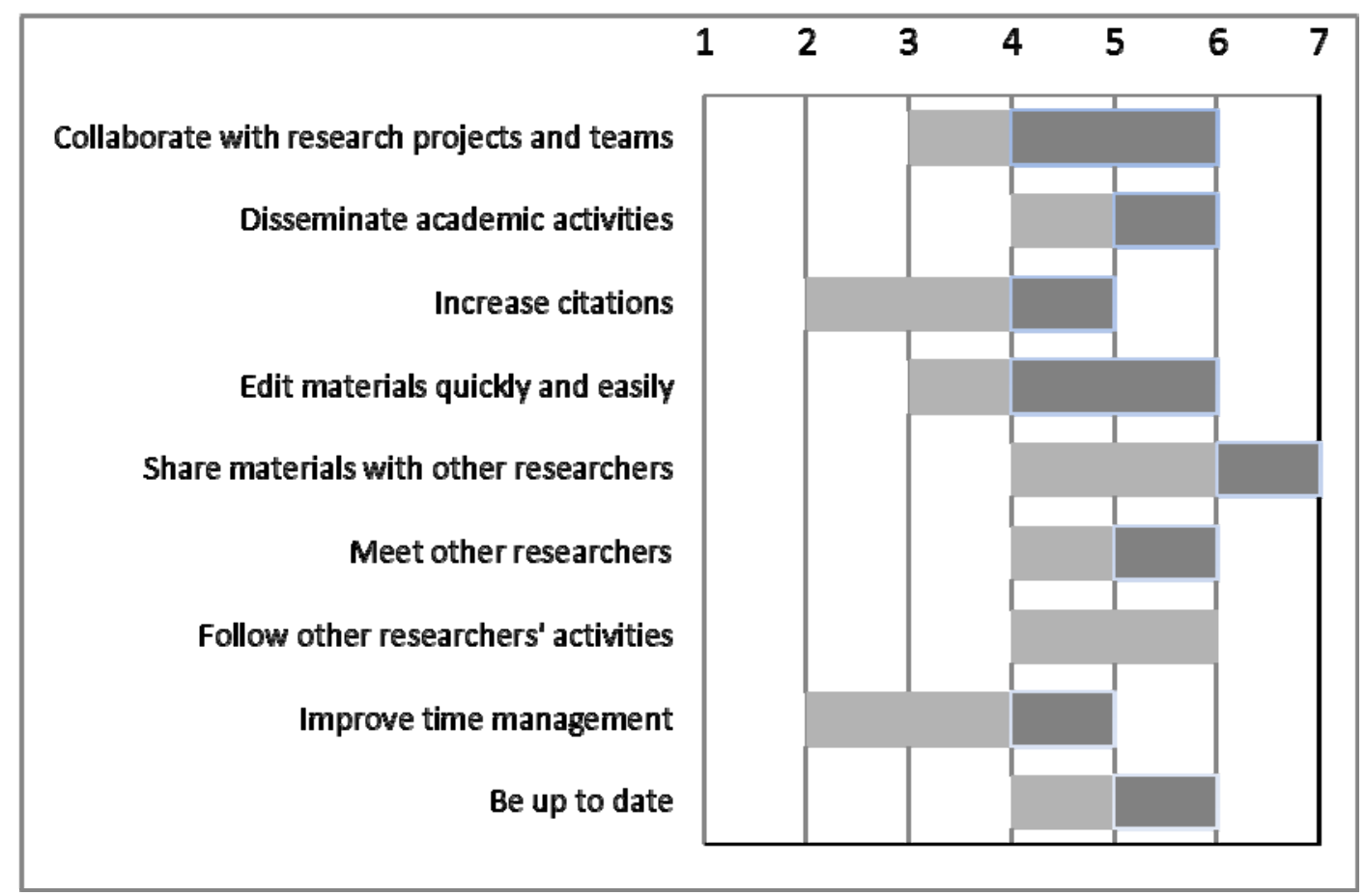

Finally, when asked whether their institutions promote the use of social media for academic purposes (for example, through training, dissemination of available tools and licensing), just $27 \%$ of the respondents replied affirmatively.

Twenty-one people made further comments in the open-ended question at the end of the survey. Mainly, they complained about the lack of institutional support for the use of social media, particularly given the considerable effort required to familiarise oneself with these tools and to update profiles.

\section{Discussion}

\section{Demographic profile of the social network users}

Approximately six out of ten Catalan users of Academia.edu are males. This ratio is similar to the distribution of lecturers by sex at the twelve Catalan universities considered. According to the Spanish National Institute of Statistics (INE, 2011), in academic year 2009-2010 there were 22,725 lecturers in these twelve universities, 62\% of them were males and $38 \%$ females. According to these results, there are no sex differences in use of the social network.

However, it should be taken into account that lecturers are not the only users of the social network. The analysis of the profiles and the answers to the questionnaire show that about half of the service users are lecturers and a third are $\mathrm{PhD}$ students. Although it is extremely difficult to compare these data with that of the whole population, there seems to be a certain degree of correspondence between them. According to the National Institute of Statistics (INE, 2011), in academic year 2009-2010 there were 13,501 $\mathrm{PhD}$ students at the twelve Catalan universities, i.e. a ratio of $1.7 \mathrm{PhD}$ students per lecturer; the same ratio of $\mathrm{PhD}$ students that use the social network per lecturer. 
This is a postprint (final draft post-refereeing) of an article accepted for publication in The Electronic Library 31 (6), 781-791, 2013

The high number of $\mathrm{PhD}$ students with a profile on the social network is related to the fact that users are mostly young, with $61 \%$ of them being under 40 . This result is consistent with the RIN report (2010), which shows that junior and younger academics are more likely to be social network users, whereas high use of other Web 2.0 tools is associated with older age groups and those in senior positions.

By field of knowledge, most users were social sciences scholars, who accounted for nearly half of the survey respondents, followed by researchers in the arts and humanities. Unfortunately, we do not have comparable data for the whole population of Catalan academics, but the representation of these fields can be considered higher than expected. This is in agreement with the statement in Rowlands et al. (2011) that "humanities and social science scholars avail themselves most of social media".

\section{Reasons for using the social network}

The reasons for using the service are those expected for a social networking site. Users mainly want to get in touch with other academics, disseminate their research results and follow other researchers' activities. However, the analysis of user profiles suggests that academics do not take full advantage of the services available to meet these aims. Thus, just a quarter of users upload at least one publication to their profile. Among those who do upload papers, the number of documents uploaded is not very high. However, there is evidence of a small number of very active users. Regarding the degree of connectivity with other researchers, most users follow less than ten academics and a quarter of users do not follow anybody at all.

There may be several reasons for this apparent lack of coincidence between the stated reasons for using the service and the real data on its use derived from an analysis of the profiles. Although users create a profile to achieve the goals they have in mind, they probably do not have time to constantly update their information, upload publications, connect with other researchers and so on. This hypothesis seems to be corroborated by the low intensity of use, with most users just visiting their profile when they receive an email from the service, and the short periods of time invested in the visits, together with some of the replies to the final open-ended question complaining about the huge amount of effort needed to maintain these tools.

Despite these difficulties, results suggest that users value the marketing potential of social networking sites. As Van Zyl (2009) points out, social networks offer an excellent framework for users to display their knowledge, experience and expertise. At the same time, social feedback through the contact lists associated with these tools allows the creation of a digital reputation that can place a value on an academic's knowledge and satisfy desires for prestige and recognition. It is interesting that a high proportion of users sign up for the service to disseminate their curriculums. Some users also indicate that their profile serves as a personal website or allows them to find out more about their web visibility, since the service informs them when their profile is viewed as a result of a search engine search.

Interestingly, a fifth of the users do not have any aim in mind when they create their profile, but just want to be present as other colleagues are on the site or have invited them to join. 
This is a postprint (final draft post-refereeing) of an article accepted for publication in The Electronic Library 31 (6), 781-791, 2013

\section{Use of other social media and their benefits}

When respondents were asked about their use of other social media for academic purposes, they mentioned three services in particular: citation indexes, document creation, edition and sharing tools, and communication tools. In addition, reference management and time management tools were widely used. The high use of citation indexes was to be expected, due to their importance in literature searches. Although citation indexes are not strictly a social media tool, they were included in the survey since they are increasingly common in social media. For example, Google Scholar has an option to create an author's profile. The remaining results coincide with those of Rowlands et al. (2011), who found that the most popular tools are those that allow collaborative authoring, conferencing, and scheduling and meeting.

Users particularly value the utility of social media to share materials and follow other researchers' activities. These are the same aims that they value in their use of social networks. To a lesser extent, they value social media tools to disseminate their academic activities, meet other researchers and remain up-to-date in their fields of knowledge. Interestingly, although users state that they use social media to improve their time management, they do not think that these tools help them to achieve this aim. Similarly, although users seem to value the use of social networks for marketing purposes, such as the dissemination of their research output or their curriculum, they do not believe that these tools help them to increase the number of citations they receive.

The lack of institutional support for the use of these tools is not surprising, since university libraries are not present in social media environments, as shown by a series of focus groups conducted by Nicholas et al. (2011). If social media are to be used by scholars, there is a need to define who is responsible for these tools in the academic environment and leadership is required to achieve something strategic.

\section{Conclusion}

This case study analysed the demographic profile of the users of an academic social network, their reasons for using the service and their use of other social media. The results show that users are mainly lecturers and $\mathrm{PhD}$ students. They are young and mostly from the social sciences and the arts and humanities. There seems to be no sex differences in the use of social networks.

Users mainly employ social networks to get in touch with other academics, disseminate their research results and follow other researchers' activities, although an analysis of the user profiles suggests that they do not take full advantage of the services at their disposal, probably due to the effort that needs to be made. They value the marketing potential of social networks and use them accordingly, although there is a group of users who do not have any purpose in mind when they create their profile, but just want to join other colleagues on the site.

Citation indexes, document creation, edition and sharing tools, and communication tools are other social media that are widely used by scholars. Academics value social media to share materials and follow other researchers' activities. In general terms, users complain about the lack of institutional support for the use of these tools. Therefore, it is essential to define who is responsible for social media in the academic environment and leadership is required to use these tools strategically. 
This is a postprint (final draft post-refereeing) of an article accepted for publication in The Electronic Library 31 (6), 781-791, 2013

\section{References}

Boyd, D.M. and Ellison, N.B. (2008), "Social Network Sites: Definition, History, and Scholarship", Journal of Computer-Mediated Communication, Vol. 13 No 1, pp. 210-230.

Gu, F. and Widén-Wulff, F. (2011), "Scholarly communication and possible changes in the context of social media: a Finnish case study", The Electronic Library, Vol. 29 No 6, pp. 762-776.

INE. (2012), "Estadística de enseñanza universitaria", available at: http://www.ine.es (accessed 8 March 2012).

Kaplan, A. M. and Haenlein, M. (2010), "Users of the world, unite! The challenges and opportunities of Social Media", Business Horizons, Vol. 53 No. 1, pp. 59-68.

Nicholas, D., Williams, P., Rowlands, I. and Jamali, H.R. (2010), "Researchers’ ejournal use and information seeking behaviour", Journal of Information Science, Vol 36 No 4, pp. 494-516.

Nicholas, D., Watkinson, A., Rowlands, I. and Jubb, M. (2011), "Social media, academic research and the role of university libraries", Journal of Academic Librarianship, Vol. 37 No 5, pp. 373-375.

Niu, X., Hemminger, B.M., Lown, C., Adams, S., Brown, C., Level, A., McLure, M., Powers, A., Tennant, M.R. and Cataldo, T. (2010), "National Study of Information Seeking Behavior of Academic Researchers in the United States", Journal of the American Society for Information Science and Technology, Vol. 61 No 5, pp. 869-890.

OECD. (2007), "Participative Web and User-created Content: Web 2.0, Wikis and Social Networking", available at:

http://213.253.134.43/oecd/pdfs/browseit/9307031E.PDF (accessed 14 February 2012).

Procter, R., Williams, R., Stewart, J., Poschen, M., Snee, H., Voss, A. and AsgariTarghi, M. (2010), "Adoption and use of Web 2.0 in scholarly communications", Philosophical Transactions of the Royal Society A: Mathematical, Physical \& Engineering Sciences, Vol. 368 No. 1926, pp. 4039-56.

RIN. (2010), "If you build it, will they come? How researchers perceive and use web 2.0", available at: http://www.rin.ac.uk/system/files/attachments/web_2.0_screen.pdf (accessed 14 February 2012).

Rowlands, I., Nicholas, D., Russell, B., Canty, N. and Watkinson, A. (2011), "Social media use in the research workflow", Learned Publishing, Vol. 24, No 3, pp. 183-195.

Tenopir, C., King, D., Edwards, S. and Wu, L. (2009), "Electronic journals and changes in scholarly article seeking and reading patterns", Aslib Proceedings: New Information Perspectives, Vol. 61 No 1, pp. 5-32.

Van Zyl, A.S. (2009), "The impact of Social Networking 2.0 on organisations", The Electronic Library, Vol. 27 No. 6, pp. 906-18. 